\title{
Advocating for the Improvement of Adolescent VCT Services in Malawi \\ J Daire
}

\section{Introduction}

The focus on adolescent sexual and reproductive health services (ASRHS) in Malawi resulted from the increased risk of adolescents to HIV/AIDS, Sexually Transmitted Infections (STIs) and complications of early pregnancies ${ }^{1}$. This threatens the health of future generations as close to half of the Malawian population are youths ${ }^{2}$, making it necessary to focus on adolescents in policy design and programme implementation of sexual and reproductive health (SRH) services and Voluntary Counselling and Testing (VCT).

The Ministry of Health (MOH) adopted the concept of comprehensive reproductive health as defined during the 1994 International Conference on Population and Development (ICPD) in Cairo. The ICPD emphasised reproductive health needs for adolescents as well ${ }^{3}$. The reproductive health unit was established in 1997 within $\mathrm{MOH}$, since then Malawi has developed several policies and guidelines in support of reproductive health service implementation. While $\mathrm{MOH}$ is responsible for providing biomedical HIV/ AIDS response, the National AIDS Commission (NAC) is the key coordinating body for both government and non governmental HIV/AIDS programmes.

Very few young people have gone for testing despite the fact thatadolescent VCT programmes have expanded considerably and awareness of available services has increased over the last few years for example in 2000 only $7 \%$ of adolescents aged 15-19 had HIV test ${ }^{6}$. Paradoxically, HIV/AIDS prevalence data shows that 15-24 year olds have the highest rate of new HIV infections ${ }^{2}$. The fact that many young people contract $\mathrm{HIV} / \mathrm{AIDS}$ but few present themselves for testing may be because of poor quality of adolescent VCT services. Although another explanation could be that young people consider themselves invulnerable, on the other hand, the adolescents' perception of their vulnerability can be changed by improving VCT services among other things. All in all adolescent VCT services in Malawi leave a lot to be desired about in terms of availability, accessibility and acceptability.

Adolescent VCT service enables and encourages adolescents with HIV to access appropriate care and is an effective HIVprevention strategy ${ }^{4}$. This article therefore, advocates for improvement of adolescent VCT services in Malawi in terms of availability, accessibility and acceptability through;

- Analysing current adolescent VCT services in Malawi

- Discussing what needs to be done

- Making recommendations for improving adolescent VCT services

\section{Current adolescent VCT services in Malawi}

For the purpose of this paper, VCT services in Malawi will be described in structural, policy and programme context.

\section{Structural context}

The $\mathrm{MOH}$ is responsible for providing and coordinating health services in the country including the domains of SRH and $\mathrm{HIV} / \mathrm{AIDS}$. The $\mathrm{MOH}$ is responsible for providing clinical aspects of HIV/AIDS service provision which are coordinated by the HIV/AIDS coordinator. There is a Principal Secretary for HIV/AIDS and Nutrition under the office of the president and cabinet that has responsibility for coordinating HIV / AIDS activities and project mainstreaming in all other government ministries.

NAC is the key coordinating body for HIV/AIDS in the country. It develops policies and coordinates all HIV/ AIDS programmes in the country whether implemented by governmentinstitutions or Non Governmental Organizations (NGOs)

NAC also develops national VCT guidelines, national training materials for counselling and HIV testing, facilitates VCT training, monitors and supervises VCT sites, evaluates VCT services, manages VCT information and is also a donor for community HIV/AIDS activities implemented by government institutions and NGOs. Its secretariat works in close collaboration with the VCT services' coordinators in each district.

At the district level, the $\mathrm{MOH}$ is headed by the District Health Office (DHO), with two sections, hospital and community health. It is under the community health section that all disease control programmes including HIV/AIDS and VCT services belong and are overseen by coordinators.

The MOH implements VCT programme through the DHO in community health section through nurses, clinicians and HIV/AIDS counsellors in hospital institutions and community nurses, HIV/AIDS counsellors and community health workers in the communities and schools. In addition to the $\mathrm{MOH}, \mathrm{NGOs}$ and private health providers also provide VCT services to adolescents such as Christian Health Association of Malawi (CHAM), Malawi Aids and Counselling Resources Organization (MACRO, the largest NGO VCT provider in Malawi), Banja La Mtsogolo, and private for profit hospitals.

There are currently two forms of VCT service delivery in Malawi; the Standalone services provided by NGOs and Integrated services run by some Government and CHAM hospitals. However HIV testing carried out in most private for profit settings is often without adequate pre-test counselling, more often as part of clinical care to confirm clinical suspicion of HIV disease ${ }^{5}$. Both stand alone and integrated adolescent VCT services are constrained by various factors including inadequate infrastructure, financial constraints and limited HIV testing capacity due to shortage of trained counsellors and supplies. This has resulted in limited coverage and access to VCT services despite an increasing demand ${ }^{5}$.

In addition to VCT there are numerous local NGOs, FBOs who are involved in VCT support activities ${ }^{6}$, most of which are project based meaning that their availability is short term because of short term funding as a result, their availability may not be consistent ${ }^{7}$.

\section{Policy context}

Policies for adolescents VCT services in Malawi are found in 
the national youth, family planning, reproductive health and the national AIDS policies.

National youth policy targets youth age of 14-25 and provides guidelines for dealing with HIV/AIDS and VCT. It also calls for the participation of the adolescents in decision making process and planning for implementing VCT services for adolescents $^{2}$.

Family planning policy recognizes the right of adolescents to VCT services (All persons of reproductive age regardless of marital status shall have the fundamental right to reproductive health services) according to JHPIEGO and $\mathrm{MOH}^{8}$. It also encourages adolescents to have VCT before marriage and any sexual relationship.

Reproductive health policy aims at provision of accessible, affordable, convenient and comprehensive VCT services to adolescents through informed choice in order to enable them attain their reproductive health goals and rights and it also emphasizes the need for VCT services to be adolescent friendly ${ }^{3}$.

The National AIDS policy aims at providing the necessary legal and administrative framework for the implementation of right based and multi-sectoral VCT services. It also outlines policy implementation strategies focused on the adolescents $^{6}$.

\section{Programme context}

According to Chimbiri ${ }^{2}$ Adolescent VCT programme encompasses several activities as follows;

- HIV testing

- HIV/AIDS counselling

- Information Education Communication (IEC) on HIV which focuses on information about HIV/AIDS: definitions, modes of transmission, prevention, risks and advantages of VCT

- Behaviour change communication (decision making, self esteem and negotiation skills)

- Distribution of condoms

- Community sensitization

- HIV/AIDS youth clubs

- School curriculum based VCT services orientation

- $\quad$ Skills development

Although these adolescent VCT programmes have expanded considerably and awareness of available services has increased over the last few years, very few young people have gone for testing, for example in 2000 only $7 \%$ of adolescents aged 15-19 had ever had HIV test ${ }^{6}$. This leaves a lot to be desired about adolescent VCT service in Malawi in terms of availability, accessibility and acceptability. The following is the analysis of quality of adolescent VCT services in Malawi in terms of availability, accessibility and acceptability.

\section{Availability}

$\mathrm{MOH}^{5}$ states that adolescent VCT services in Malawi are constrained by various factors including inadequate infrastructure, financial constraints and limited HIV testing capacity due to shortage of laboratory technicians and supplies. This has affected availability of VCT services to the extent that;
- There is a high demand for adolescent VCT services ${ }^{2}$

- Lack of VCT centres in populated rural areas ${ }^{8}$

- Adolescent VCT support services in Malawi are inconsistent in areas where NGO is the only provider ${ }^{5}$ due to projectized activities by both international and local NGO based on availability of funding

- Stand alone VCT services by private sector which do not meet adolescent multidimensional needs ${ }^{8}$

\section{Accessibility}

Most Malawians within the sexually active age group have not had access to VCT services and therefore do not know their HIV sero-status, although HIV/AIDS prevalence data shows that 15-24 year olds have the highest rate of new HIV infections ${ }^{6}$. Access to VCT services in Malawi similar to availability has been constrained by inadequate infrastructure, financial resources and limited HIV testing capacity due to shortage of trained counsellors and supplies ${ }^{5}$. This has resulted in the following among adolescents;

- Low levels of knowledge and awareness about availability of VCT services

- Adolescent VCT services not being private, confidential and in spacious infrastructure

- Adolescent VCT services not being in convenient or comfortable locations or surrounding

- Adolescent VCT services not done during convenient times

\section{Acceptability}

Since young people are often reluctant to attend formal reproductive health services, this led to development of youth-friendly health services (YFHS) and innovative approaches to integrating VCT with youth culture such as music and drama to support adolescent VCT services in Malawi. However, Chimbiri ${ }^{2}$ and Munthali $^{6}$ states that lessons from VCT clinics reveal that;

- Adolescents feel unwelcome by the providers

- Young people rely more on informal sources of information and counselling outside the health system like friends, media and private providers.

- Young people feel service providers are not of their age and sex, not respectful, do not understand them, do not have time to listen to them, do not have high standards, and do not have adequate knowledge and experience working with young people.

- Young people feel left out in the process of developing VCT programmes

- Young people do not attend VCT centres because of fear of their parents and guardians.

\section{Why improve VCT services for adolescents?}

Firstly, it is important that adolescent VCT services are improved to meet adolescents' needs as the future generation depends on them. Secondly, more adolescents alive today than ever before world wide, 1.1 billion adolescents aged $10-19$ years of which $85 \%$ live in developing countries ${ }^{4}$. In Malawi adolescents comprise $23 \%$ of the total population, and the majority live in rural areas and $12 \%$ of the population age 15-49 is now living with $\mathrm{HIV}^{9}$. Thirdly, HIV/AIDS is now the leading cause of death of the productive age group and young people aged 15-24 account for more than 50 percent of all HIV infections worldwide ${ }^{10}$. 
Improving adolescent VCT services is therefore, particularly urgent in Malawi for the following reasons;

- Young people have high rates of HIV infection and need access to testing, prevention, counselling and care for HIV ${ }^{11}$

- $\quad$ VCT is now a component of HIV/AIDS prevention and treatment, it provides an entry point to other HIV related care and support services such as PMTCT, diagnosis and management of STIs, Tuberculosis (TB) treatment, anti-retroviral Therapy (ART) and nutritional support ${ }^{5}$

- Knowledge of one's HIV status and the associated HIV specific counselling provides a catalyst for HIV risk free behaviour change making it an effective HIV-prevention strategy ${ }^{8}$, though there is still no hard evidence on the relationship between VCT and long term prevention of HIV

- Extrapolating from Munthali et $\mathrm{al}^{6}$, the future course of Malawian AIDS epidemic depends on a number of important variables including the level of awareness about HIV/AIDS and access to services for VCT and STIs treatment especially among the adolescents and productive age group

\section{What needs to be done according to literature?}

The improvement of adolescent VCT services in Malawi will be discussed in terms of availability, accessibility and acceptability in this paper.

\section{Availability}

According to literature, adolescent VCT services can be made available by firstly committing adequate resources to the development policies and strategies. This will expand VCT programmes, improve infrastructure, train more staff, provide adequate supplies, increase HIV/AIDS campaigns and integrate VCT with other services.

The success of increasing the availability of adolescent VCT services just like any other service depends to a large extent on availability of sufficient resources (infrastructure, human capacity and supplies) and sustained source of funding ${ }^{12,13}$. Therefore, policy makers and the key players need to commit adequate resources for formulated policies to be carried out and expand VCT services to reach adolescents in the rural areas where the masses are and are difficult to reach areas. Furthermore, a sustained source of funding remains the onus of the implementers depending on their financial management especially accountability both to the donors and beneficiaries. If resources are misused both international and local donors withdraw and it is the beneficiaries that suffer. At the same, donor including NAC need to develop robust finance monitoring strategies to ensure that resource trickle down to the intended beneficiaries ${ }^{14}$.

On the other hand, establishing linkages with other VCT providers can create a broad network of service delivery options to which adolescents can be referred. In addition, integration of adolescent with other services like family planning, treatment of STIs and provision of anti-retroviral therapy should be scaled up because adolescents look for options ${ }^{15}$.

\section{Accessibility}

Access to VCT services currently limits access to interventions for people with HIV. As adolescents VCT services are being scaled up in Malawi, districts should develop strategies to increase access to VCT services in remote populations such as those in rural areas, for example providing mobile VCT services. Mobile VCT services have been developed in an attempt to access hard-to-reach individuals ${ }^{7}$. Although there are cautions in using youth centers for VCT including ensuring confidentiality, testing quality and providing adequate referral networks for positive young people there is room to increase the delivery of counselling through youth centre ${ }^{5}$.

\section{Acceptability}

Training of VCT service providers should provide participants with an awareness of adolescent's rights to be treated respectfully, in addition to providing the necessary technical information and skills ${ }^{16}$.

VCT programmes for adolescents should engage adults as positive reliable sources of information ${ }^{16}$. This means that programmes need to strengthen parents and other adults' abilities to provide accurate information and skills for HIV prevention and VCT services. This has proved to expand coverage of VCT information and remove adolescents' fear of parents and guardians as a barrier to VCT services ${ }^{17}$.

VCT service providers and planners should work with adolescents from planning to implementation phases of VCT services to determine where and how adolescent spend time, obtain VCT information and services. Then VCT programmes would be designed to use approaches favoured by adolescents in so doing, making the programmes most likely to be used by the adolescents. Adolescents are also likely to participate and use programmes which involve them from the planning to implementation stage ${ }^{16}$.

Information on the available VCT services and general information on HIV/AIDS, presented in contexts that adolescents find meaningful and comfortable such as the media, discussion groups, clubs, peer-education groups, drama competitions, soap operas and comic books in order to increase information accessibility and accuracy ${ }^{16}$. This is on the basis that adolescents are poorly informed and that they often seek sexual and reproductive health information and services through sources other than formal health programmes $^{15}$.

\section{Conclusion and Recommendations}

Although adolescent VCT programmes have expanded considerably and awareness of available services has increased over the last few years, very few people have gone for testing. This leaves a lot to be desired about the quality of adolescent VCT service in Malawi in terms of availability, accessibility and acceptability which are issues of quality. High-quality VCT enables and encourages adolescents with HIV to access appropriate care and is an effective HIV-prevention strategy. In order to contribute to the improvement of the quality of adolescent VCT services this paper has analysed current adolescent VCT services in Malawi, reviewed literature on improving adolescent VCT services and the following are its recommendations;

- Policy makers and the key players should commit adequate resources for formulated policies to be carried 
out and to expand VCT services to reach adolescents in the rural areas.

- The MOH and the other key players strengthen the linkage between public and private sector in order to increase both the coverage and the quality of VCT services for adolescents in so doing meeting the multidimensional and growing demand

- Districts should develop strategies to increase access to VCT services in hard to reach populations such as those in rural areas

- VCT service providers training should include adolescent's rights and skills for interacting with them in a respectful way, in addition to the technical information and skills

- VCT programmes for adolescents should engage adults as positive reliable sources of information and actors to expand coverage of VCT information and remove adolescents' fear of parents and guardians as a barrier to VCT services

- VCT service providers and planners should work with adolescents from planning to implementation phases of VCT services so that VCT programmes would be designed to use approaches favoured by adolescents in so doing making the programmes most likely to be used by the adolescents.

- Information on the available VCT services and general information on HIV/AIDS, should be presented in contexts that adolescents find meaningful and comfortable

- IEC and behavioural change communication activities in VCT services for adolescents should include training in building life skills, both generic and those specific to reproductive health, because HIV/AIDS knowledge alone is not sufficient to ensure the adoption of risk free health behaviour e.g. VCT

- There is need for more research and specific data to highlight the gap in meeting of adolescents' needs for VCT information and services.

- VCT programmes should be monitored, evaluated and documented to ensure that their challenges are understood and their successes replicated for effective implementation of VCT services in Malawi. In addition, beyond evaluating programmes, adolescent SRH policy process as well should be evaluated

\section{References}

1. Advance Africa (2003) Best Practices Update: Best practices in adolescents reproductive health. [Online]. Advance Africa. Available from the World Wide Web: <http://www.advanceafrica. $\mathrm{rg} /$ publications_andpresentations/Best_Practices_Updates/BP Updates_ARH.pdf $>$ (accessed 21 January 2005).

2. Chimbiri, A.M. (2004) Adolescent Sexual and Reproductive Health and HIV Prevention in Malawi. [Online]. Centre for reproductive health. Available from the World Wide Web: <http://www.med. cfrh/tematisk/globinf\%20serminar/Adolescent\%20serminar2004/ chimbiri.pdf $>$ (Accessed 17 January 2005).Bartholomeeusen, S., Aantjes, C. and Mann, G. (2002) MBN HIV/AIDS Evaluation; Country Report, Malawi (Final Version) ACE Europe

3. Ministry of Health (2002) Reproductive health policy. February 2002. Ministry of Health and Population in Malawi. Lilogwe

4. Boswell, D. and Baggaley, R. (2002) Voluntary Counselling and Testing (VCT) and Young people: A summary overview. Family Health International. Unpublished

5. Ministry of Health (2004) HIV Rapid Test Handbook. February 2004. Ministry of Health and Population in Malawi. Lilongwe

6. Munthali, A.C., Chimbiri, A. and Zulu, E. (2004) Adolescent Sexual and Reproductive Health in Malawi: A Synthesis of Research Evidence Occasional Report No. 15 December 2004. The Alan Guttmacher Institute. New York and Washington

7. Hargreaves NJ, Chimzizi RB, Golombe C, Munthali F, Kajawo E, Salaniponi FM. (2002) Improving the quality of voluntary counselling and HIV testing services in Malawi using the UNAIDS VCT Quality Evaluation Tools. Int Conf AIDS. 2002 Jul 7-12; 14: abstract no. MoOrF1078. Malawi National TB Control Programme, Lilongwe, Malawi

8. Ministry ofHealth (2005) Report on ACountry-Wde Survey ofHIV/ AIDS services in Malawi for the Year 2004. HIV Unit, Department of clinical services, MOHP; National AIDS Commision

9. ational Statistics Office (2004) Malawi Demographic and Health Survey2004. National statistics office, Zomba, Malawi

10. Croce-Galis, M. (2004) Protecting the Next Generation: Understanding HIV risk among the youth. [Online].Guttmancher. Available from the World Wide Web $:<$ http://www.guttmancher. org/pubs/rib/2004/12/20/rib3-04.pdf> (Accessed 21 January 2005).

11. McCauley, A.P McCauley AP, Crowley S, Juma M, Denison J. Int Conf AIDS. 2004 Jul 11-16; 15: abstract no. MoOrE1070. Horizons Program/International Center for Research on Women, Washington, DC, United States

12. Cheema, G. and Rondinelli, D. (1983) Decentralization and Development Policy implementation in developing countries. London: Sage.

13. Bonnal, J. (2003) Decentralization in developing Countries: Case Studies. [On line]. United Nations. Available from the World Wide Web: < http://www.un.org/decentralisation/English/Case Studies/ guinea_e.html $>$ [Accessed 18 June 2005].

14. Hughes, J. and MacCauley, A.P. (1998) Improving the fit: Adolescents needs and future programmes for sexual and reproductive health in developing countries. Studies in Family Planning, 29(2), 2333-245.

15. JHPIEGO and Ministry of Health and Population of Malawi (2001) Malawi national reproductive health service delivery guidelines. October 200. JHPIEGO and Ministry of Health and Population in Malawi. Lilongwe

16. Munthali A., Kadzandira J. and Mvula P. (2003) Formative study on prevention of mother to child transmission of HIV, Lilongwe, Malawi: UNICEF, Ministry of Health and Population and National AIDS Commission, 2003.

17. Rivera, R. et al (2001) Contraception for Adolescents: Social, clinical and service-delivery considerations. International Journal of Gynaecology and Obstetrics, 75, 149-163.

18. Rondinelli, D. et al. (1993) Decentralization in Developing Countries. A review of recent experience. Word Bank Working Papers. Number 581, Management and Development series Number 8. wshington D.C.: World bank.

19. Siddiqua, Y. and Kabir, M. (2002) Adolescent Reproductive Health: What are the lessons learnt from the intervention projects. [Online]. UNESCAP. Available from the World Wide Web: <http:// www.unescap.org/esid/population/journal/2002/v17no3dn.pdf $>$ (Accesses 17 January 2005). 